\title{
Individual cow variation on milk polyunsaturated fatty acids
}

\author{
S. Stergiadis ${ }^{1}$, C. Leifert ${ }^{1}$, C. J. Seal ${ }^{2}$, M. D. Eyre ${ }^{1}$ and G. Butler ${ }^{1}$ \\ ${ }^{1}$ Nafferton Ecological Farming Group, School of Agriculture Food and Rural Development, Newcastle University, Nafferton \\ Farm, Stocksfield, Northumberland, NE43 7XD, UK and ${ }^{2}$ Human Nutrition Research Centre, School of Agriculture, Food \& \\ Rural Development Newcastle University, Newcastle upon Tyne, NE1 7RU, UK.
}

Milk fat composition is influenced by dairy feeding with grazing and oilseed supplementation recognised as means of elevating polyunsaturated fatty acids (PUFA) concentration in milk. Differences in PUFA content of milk have been reported between farming systems ${ }^{(1)}$, dairy 'brand' as well as season and year of production ${ }^{(2)}$ ). However, such studies using milk bulked from a number of cows or farms give no indication of variation between individual cows and hence the scope for selective breeding to increase milk PUFA content is reduced.

Milk collected during two feeding trials was used to assess individual variation in cows' response to feeding practices aimed at increasing the PUFA content of winter milk. Rapeseed and two levels of linseed supplementation were compared with control diets, against the background of both organic and conventional management. Milk fatty acid (FA) profiles of individual milk samples were determined by gas chromatography $\left.{ }^{(2)}\right)$.

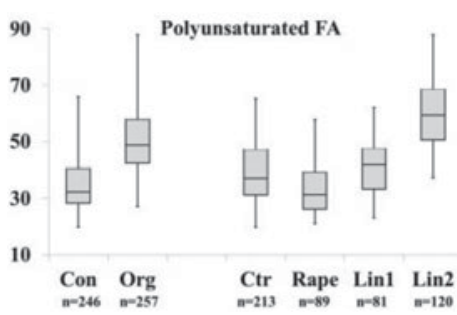

Fig. 1. Variation ( $\max$ and min values \& interquartile range; bar $=$ median) for PUFA.

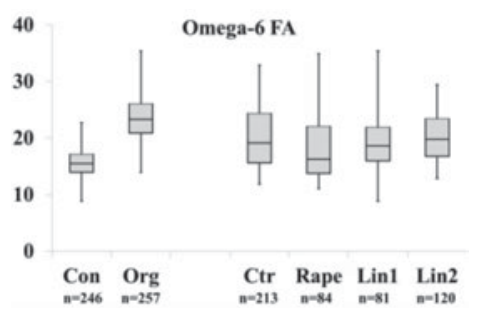

Fig. 2. omega-6 FA (n-6)

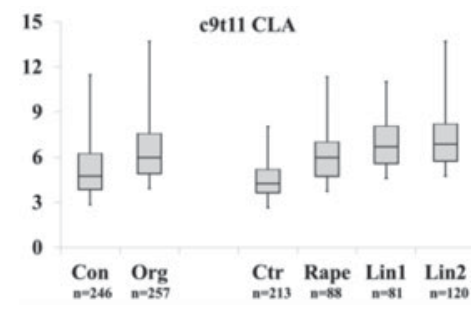

Fig. 3. conjugated c9t11 C18:2 (c9t11 CLA)

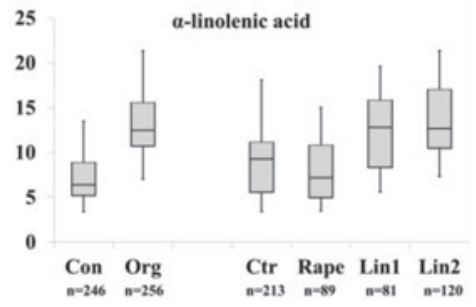

Fig. 4. $\alpha$-linolenic (ALA), and long chain omega-3 FA (LC n-3).

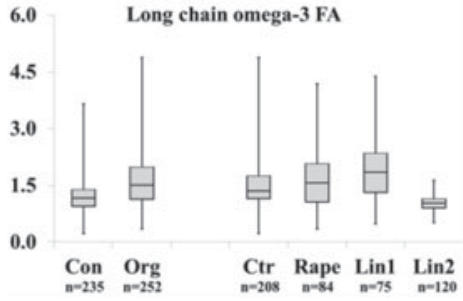

Fig. 5. in milk (Con; conventional, Org; organic), where control diets (Ctr) were supplemented with linseed ( $\operatorname{Lin} 1 ; 1.5 \mathrm{~kg} / \mathrm{cow}$ per day, $\mathrm{Lin} 2 ; 2.0 \mathrm{~kg} / \mathrm{cow}$ per day) or rapeseed (Rape; $1.2 \mathrm{~kg} / \mathrm{cow}$ per day).

Comparing the range between $1^{\text {st }}$ and $3^{\text {rd }}$ quartile relative to median concentrations, $n-6$ and PUFA were more consistent across treatments than c9t11 CLA and $n-3$, although, due to their higher levels, the ranges were actually greater in absolute terms.

Generally, diets expected to increase milk PUFA concentrations (organic production or oilseed feeding) did result in a wider range of $n-3$ and c9t11 CLA concentrations, suggesting some cows showed a better response to this opportunity. The unexplained exception to this statement relates to cows on the high linseed diet, showing depressed and more uniform milk LC $n-3$ concentrations.

Results suggest challenging cows with elevated dietary PUFA allows the opportunity for some to express their superior ability to transfer $n-3$ and CLA into milk, although care might be needed to interpret LC $n-3$ results.

We are grateful for funding from the EU (Quality Low Input Food and Low Input Breeds projects), Greek State's Scholarship Foundation and Yorkshire Agricultural Society.

1. Stergiadis S, Seal C, Leifert C et al. (2012) J. Agric. Food Chem. 60, 7270-7281.

2. Butler G, Stergiadis S, Seal C et al. (2011) J. Dairy Sci. 94, 24-36. 